\title{
Investigation of a novel oral airway for awake flexible bronchoscopy
}

\author{
William P. McKay, MD (1) - Trevor Krysak, BSc • Chung-Chun Tyan, MBBS
}

Received: 10 March 2020/Revised: 4 April 2020/Accepted: 4 April 2020/Published online: 20 April 2020

(c) Canadian Anesthesiologists' Society 2020

\section{To the Editor,}

Awake intubation of the difficult airway is most often performed using a flexible bronchoscope (FB). ${ }^{1,2}$ The recently described novel McKay airway is designed to maintain jaw thrust during airway management. ${ }^{3}$ We report an interventional crossover study of airway devices as used by novice bronchoscopists in awake participants. With University of Saskatchewan Ethics Board approval (\#BIO18-08; 13 September 2017), and written informed consent of both patients and the proceduralist participants, we compared the McKay airway with a standard bite block (Conmed Bite Block; ConMed Endoscopic Technologies Corp, Utica, NY, USA) and with a Williams airway (Figure). The primary outcome of the study was the procedural time from insertion of the FB tip into the airway until vocal cords were fully visualized. We also recorded the bronchoscopist's comments (regarding quality of glottic view) and any occurrence of patient gagging.

Study participants were residents and medical students learning bronchoscopy and a convenience sample of 71 patients scheduled for awake diagnostic bronchoscopy. Procedures were supervised by an attending respirologist as is the normal clinical practice for learners at our centre. Patients' airways were topicalized by gargling lidocaine $2 \%$ solution prior to additional spraying of lidocaine $2 \%$.

W. P. McKay, MD ( $₫) \cdot$ T. Krysak, BSc

Department of Anesthesia, University of Saskatchewan, Saskatoon, SK, Canada

e-mail: bill.mckay@usask.ca

C.-C. Tyan, MBBS

Division of Respirology, Sleep Medicine, and Critical Care, University of Saskatchewan, Saskatoon, SK, Canada
Low-dose intravenous sedation with midazolam and fentanyl was given according to clinical morbidity.

We enrolled 73 patients, although two were removed from the study before airway insertion as one became confused after light sedation, and one was unable to lie supine because of back pain (from spinal metastases). The 36 female and 35 male patients that completed the study had a mean (standard deviation) age of 62 (17) yr. Seventyone subjects had a McKay airway, 71 had a bite block, and 61 had a Williams airway inserted. The McKay airway group had a shorter median [interquartile range] time for viewing the vocal cords compared with the bite block group (10.5 [6.7-16.0] sec vs 11.4 [9.0-29.8] sec, respectively; $P=0.02$ ), but not faster than Williams ( 9.5 [6.2-14.8] sec; $P=0.76$ ).

Gagging occurred in 1/71 (1.4\%) with McKay airway. versus $11 / 55(20 \%)$ with Williams airway $(P<0.001)$, and in none with the bite block $(P=0.32$, compared with McKay). The McKay airway caused mild, brief gagging in one patient with a very sensitive gag reflex, but this did not preclude its use. The bronchoscopists' comments noted that the quality of glottic view was optimal in 14 of the 71 (20\%) McKay airway patients compared with only one of $71(1.4 \%)$ bite block patients $(P<0.001)$, and three of the $55(6 \%)$ Williams airway patients $(P<0.001)$.

Gagging impairs the performance of awake bronchoscopy. As the McKay does not touch the posterior pharynx, it requires less intense topical anesthesia and reduces the incidence of gagging. The improved glottic view with the McKay airway was likely a result of a more fully opened supraglottic space. A largediameter endotracheal tube (ETT) cannot pass through the Williams airway, and the ETT connector must be removed to slide the Williams out of the mouth after intubation. In contrast, when the FB is in the trachea, the McKay airway 


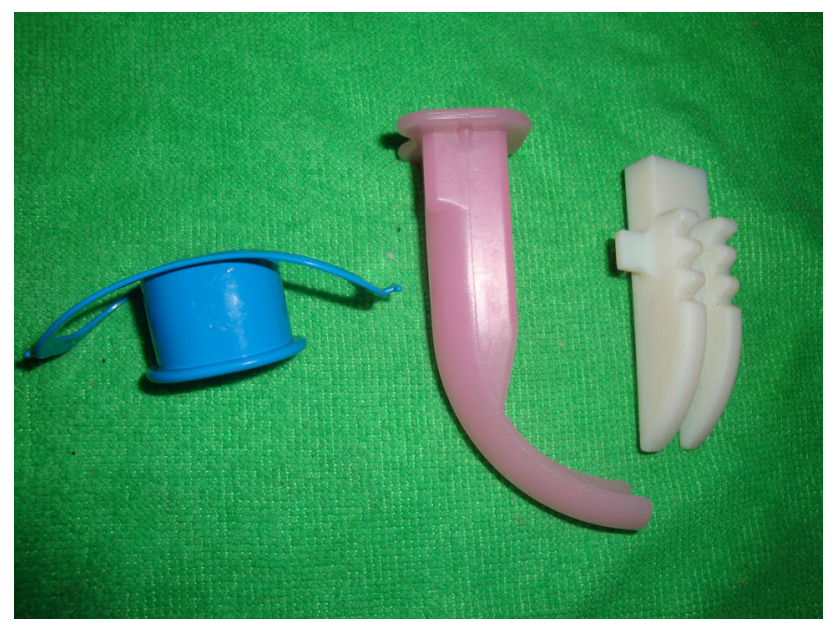

Figure Oropharyngeal airways studied during awake flexible bronchoscopy. Left to right: standard bite block, Williams airway, McKay airway

can be slipped aside, allowing unrestricted passage of any size ETT with connector in place. The McKay was designed for bag-mask ventilation, ${ }^{3}$ but may be useful in awake intubation. Nevertheless, as we only studied glottic visualization, the ability of the McKay airway to result in faster and more successful awake intubation needs to be determined by future studies.

Conflicts of interest William P. McKay has a vested interest in the device although the patent is owned by the University of Saskatchewan.

\section{Funding statement None.}

Editorial responsibility This submission was handled by Dr. Hilary P. Grocott, Editor-in-Chief, Canadian Journal of Anesthesia.

\section{References}

1. Levine AI, Leibowitz AB. Flexible bronchoscopy still the definitive standard for airway management. Anesthesiology. 2013. https://doi.org/10.1097/ALN.0b013e31827bd239.

2. Collins SR, Blank RS. Fiberoptic intubation: an overview and update. Respir Care 2014; 59: 865-78; discussion 878-80.

3. McKay WP. Description of a novel oral airway: the McKay airway. Can J Anesth. 2020. https://doi.org/10.1007/s12630-02001626-3.

Publisher's Note Springer Nature remains neutral with regard to jurisdictional claims in published maps and institutional affiliations. 